Article

\title{
Enhanced Subcellular Trafficking of Resveratrol Using Mitochondriotropic Liposomes in Cancer Cells
}

\author{
Ji Hee Kang and Young Tag Ko *(i) \\ College of Pharmacy and Gachon Institute of Pharmaceutical Sciences, Gachon University, Incheon 21936, Korea \\ * Correspondence: youngtakko@gachon.ac.kr; Tel.: +82-32-820-4923; Fax: +82-32-820-4829
}

Received: 14 May 2019; Accepted: 16 August 2019; Published: 20 August 2019

\begin{abstract}
Mitochondria are membrane-enclosed organelles present in most eukaryotic cells, described as "power houses of the cell". The mitochondria can be a target for inducing cancer cell death and for developing strategies to bypass multi drug resistance (MDR) mechanisms. 4-Carboxybutyl triphenylphosphonium bromide-polyethylene glycol-distearoylphosphatidylethanolamine (TPPDSPE-PEG) and dequalinium-polyethylene glycol-distearoylphosphatidylethanolamine (DQA-DSPEPEG) were synthesized as mitochondriotropic molecules. Mitochondria-targeting liposomes carrying resveratrol were constructed by modifying the liposome's surface with TPP-PEG or DQA-PEG, resulting in TLS (Res) and DLS (Res), respectively, with the aim to obtain longer blood circulation and enhanced permeability and retention (EPR). Both TLS (Res) and DLS (Res) showed dimensions of approximately $120 \mathrm{~nm}$ and a slightly positive zeta potential. The enhanced cellular uptake and selective accumulation of TLS (Res) and DLS (Res) into the mitochondria were demonstrated by behavioral observation of rhodamine-labeled TLS or DLS, using confocal microscopy, and by resveratrol quantification in the intracellular organelle, using LC-MS/MS. Furthermore, TLS (Res) and DLS (Res) induced cytotoxicity of cancer cells by generating reactive oxygen species (ROS) and by dissipating the mitochondrial membrane potential. Our results demonstrated that TLS (Res) and DLS (Res) could provide a potential strategy to treat cancers by mitochondrial targeting delivery of therapeutics and stimulation of the mitochondrial signaling pathway.
\end{abstract}

Keywords: mitochondrial targeting; triphenylphosphonium cation; dequalinium; liposomes; resveratrol

\section{Introduction}

Mitochondria are membrane-enclosed organelles present in most eukaryotic cells, and are described as "power houses of the cell" [1,2]. The mitochondria supply the cells' energy and play an important role in the regulation of the cell cycle, including cell growth, proliferation, differentiation and cell death [2,3]. Mitochondria in cancer cells are known to have structural and functional differences, such as increased and altered mitochondrial DNA, increased hexokinase production, and altered mitochondrial protein and lipid content, compared to that of normal cells [4-8]. Cancer cells also have twice the mitochondrial mass of normal cells, leading to more cellular ATP production and a greater mitochondrial potential $[2,8,9]$.

The mitochondria can be a target for inducing cancer cell death and for developing a strategy to bypass multi drug resistance (MDR) [10]. Cancer cells need high energy levels for proliferation [11], thus, mitochondria-targeting drugs can lead to cancer cell death by extensive ATP depletion [12]. In addition, the strategy to block anti-apoptotic proteins in the mitochondria can result in the activation of the cell death machinery, composed of catabolic hydrolases and proteases [10,13]. Inducing apoptosis through direct targeting of cancer cell mitochondria could be a strategy to circumvent the MDR mechanism in chemotherapy $[3,8,14]$. Therefore, mitochondria-targeting chemotherapy is receiving much attention 
and recognition, as studies have shown that it plays a key role in apoptosis and necrosis and in the regulation of cancer $[2,15,16]$.

Many mitochondrial drug delivery systems have been constructed with positively charged molecules, as the mitochondrial membranes of cancer cells are negatively charged $[17,18]$. Several studies have reported an improvement in the therapeutic efficacy of mitochondria-targeting agents, such as triphenylphosphonium cation [19], dequalinium (DQA) [2], rhodamine B [17] and mitochondria-targeting signal peptides (MTSs) [20].

4-Carboxybutyl triphenylphosphonium bromide (TPP) has a delocalized lipophilic cation as a structural feature, which can permeate mitochondrial membranes, leading to its accumulation or the facilitated access to the mitochondria [21]. The delocalized positive charge of TPP, which consists of three phenyl groups, facilitates their mitochondrial uptake driven by the highly negatively charged mitochondrial membrane of cancer cells [22].

DQA is a cationic amphiphile, which contains two cationic aminoquinaldinium rings, with delocalized charge centers [23]. This feature of DQA facilitates selective accumulation in the mitochondria of cancer cells, driven by the transmembrane electric potential [24].

Resveratrol is part of a group of compounds called polyphenols and is significantly present in grapes and red wine $[25,26]$. A huge amount of preclinical studies showed that resveratrol is a potential anticancer agent due to its chemopreventive ability in three major stages of carcinogenesis, including initiation, promotion and progression [2,27-30]. Resveratrol is able to induce cell death through the mitochondrial apoptotic pathway, in which the mitochondria play a central role in the release of pro-apoptotic factors [25,31]. However, its poor bioavailability, caused by its low water solubility, chemical instability and intestinal metabolism, are major obstacles for its use in clinical therapy $[29,30,32]$.

The PEG-stabilized liposomes have been successfully applied for the in vivo delivery of various therapeutic agents, including nucleic acids, proteins and small molecules [2,33,34]. Liposomes consist of a phospholipid-formed bilayer and can be formulated in different sizes, ranging from a few to tens of micrometers $[35,36]$. The lower size range of liposomes has been heavily studied for the treatment of diseases because of their good ability to be taken up passively by cells and in tissues [34,37]. The liposomes are highly biocompatible, display low toxicity, can be loaded with both hydrophilic and hydrophobic drugs, and can be used as gene delivery vehicles [38,39]. An additional advantage of liposomes is that they can be modified for specific purposes through the modulation of their lipid composition or the addition of functional agents, like ligands for longer circulation, targeted and enhanced permeability and retention (EPR) [35,39-41].

In this study, we propose surface-modified liposomes with TPP or DQA for mitochondria-targeted delivery of resveratrol in cancer cells (Figure 1). To modify the surface of liposomes for mitochondrial targeting, 4-carboxybutyl triphenylphosphonium bromide- polyethylene glycoldistearoylphosphatidylethanolamine (TPP-DSPE-PEG) and dequalinium-polyethylene glycoldistearoylphosphatidylethanolamine (DQA-DSPE-PEG) were synthesized as mitochondriotropic molecules (Figure 2). Mitochondria-targeting liposomes carrying resveratrol were constructed by modifying the TPP-DSPE-PEG (TLS (Res)) or DQA-DSPE-PEG (DLS (Res)) on the surface of liposomes, with the aim to obtain longer blood circulation and an enhanced permeability and retention (EPR) effect. The objectives of the present study were to prepare the mitochondria-targeting liposomes carrying resveratrol, to define the action mechanisms, and to evaluate their efficacy in treating cancer cells. 


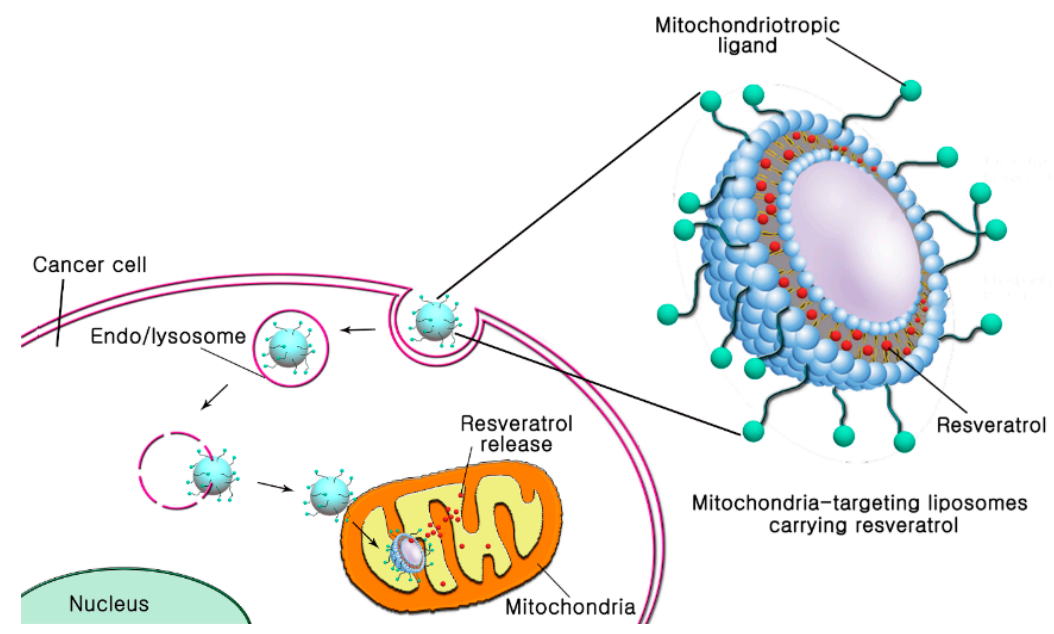

Figure 1. Schematic diagram to describe mitochondriotropic liposomes for enhanced subcellular trafficking of resveratrol in cancer cells. Mitochondria-targeting liposomes carrying resveratrol were constructed by modifying the TPP-DSPE-PEG (TLS (Res)) or DQA-DSPE-PEG (DLS (Res)) on the surface of liposomes.

(A)

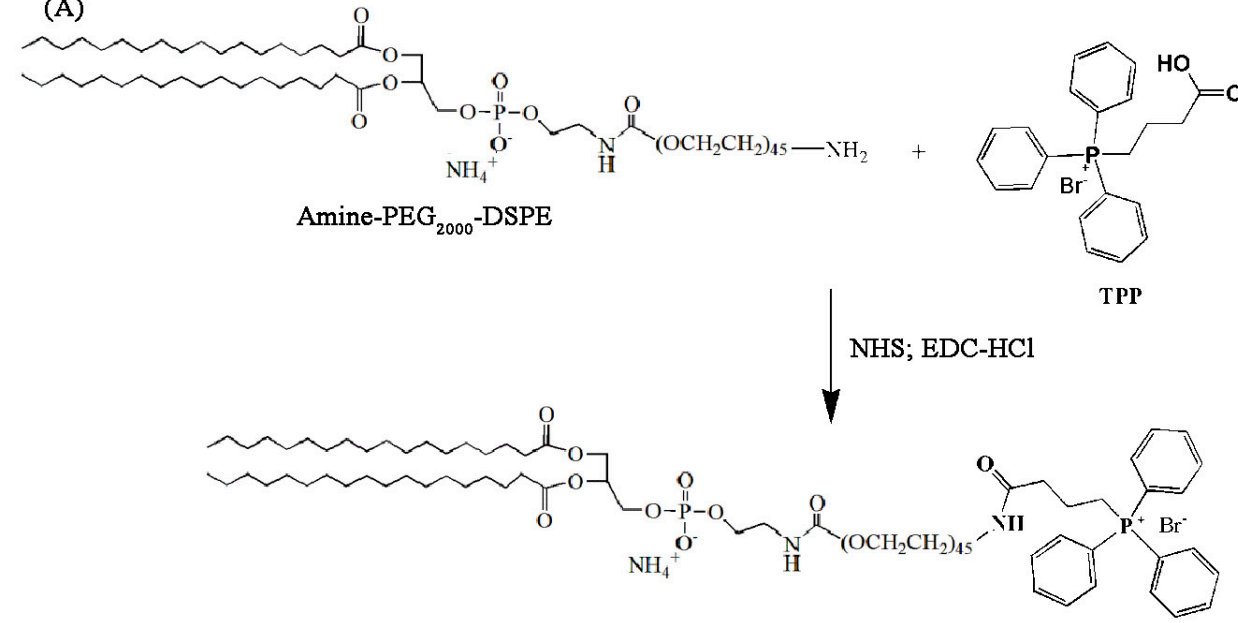

TPP-DSPE-PEG

(B)

DSPE-PEG $2000-\mathrm{COOH}$

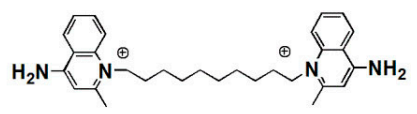

DQA

NHS; EDC-HCl

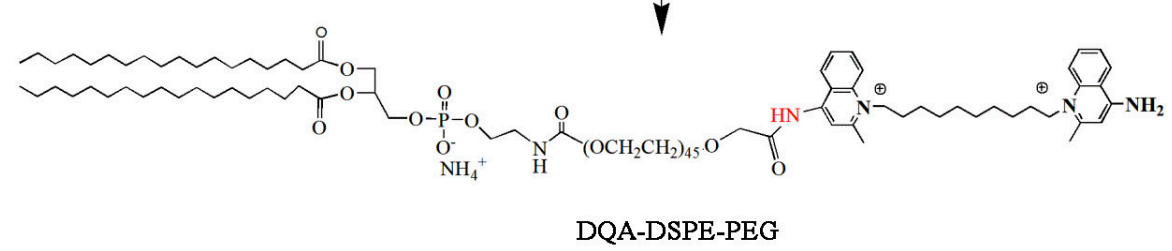

Figure 2. Synthesis scheme of TPP-DSPE-PEG (A) and DQA-DPPE-PEG (B) conjugate. DSPE-PEG $2000-\mathrm{COOH}$, 1,2-distearoyl-sn-glycero-3-phosphoethanol-amine- $N$-[methoxy(polyethylene glycol)-2000-COOH] and DQA-DPPE-PEG, dequalinium-polyethylene glycol- distearoylphosphatidylethanolamine; TPP-DSPE-PEG, 4-carboxybutyl triphenylphosphonium bromide- polyethylene glycol-distearoylphosphatidylethanolamine. 


\section{Materials and Methods}

\subsection{Materials}

1-Palmitoyl-2-oleoyl-sn-glycero-3-phosphocholine (POPC), 1,2-distearoyl-sn-glycero-3-phosphoethanolamine- $N$-[methoxy(polyethylene glycol)-2000-COOH] (DSPE-PEG $2000-\mathrm{COOH}$ ) and cholesterol were purchased from Avanti Polar Lipids (Alabaster, AL, USA). 2' ,7' -Dichlorodihydrofluorescin diacetate (DCFH-DA) was obtained from Enzo Life Sciences (Farmingdale, NY, USA). Dequalinium (DQA) and 5,5',6,6'-tetrachloro-1,1',3,3'-tetraethylbenzimidazolocarbocyanine (JC-1) were obtained from Sigma-Aldrich (St. Louis, MO, USA), and resveratrol (Res) and (4-carboxybutyl) triphenylphosphonium bromide (TPP) were obtained from Tokyo Chemical Industry (Tokyo, Japan). All other reagents were purchased from Sigma-Aldrich or Tokyo Chemical Industry (Tokyo, Japan), unless otherwise stated.

\subsection{Synthesis of TPP-DSPE-PEG and DQA-DSPE-PEG Conjugates}

DSPE-PEG $2000-\mathrm{COOH}(25 \mathrm{mg}, 0.0088 \mathrm{mmol})$ or DSPE-PEG $2000-\mathrm{NH}_{2}(25 \mathrm{mg}, 0.0088 \mathrm{mmol})$ was allowed to react for $3 \mathrm{~h}$ with EDC- $\mathrm{HCl}(3.4 \mathrm{mg}, 0.018 \mathrm{mmol})$ and NHS $(1.01 \mathrm{mg}, 0.0087 \mathrm{mmol})$ in $2 \mathrm{~mL}$ of chloroform in the presence of three drops of triethylamine at room temperature in the dark. The progress of the reaction was checked by thin-layer chromatography (TLC) on a silica gel plate. Next, dequalinium (DQA; $4.6 \mathrm{mg}, 0.0087 \mathrm{mmol}$ ) or TPP (3.9 mg, $0.0087 \mathrm{mmol}$ ) dissolved in DMSO ( $2 \mathrm{~mL}$ ) was added to DSPE-PEG2000-COO-NHS and stirred for $30 \mathrm{~min}$. Chloroform was removed by an evaporator, and $5 \mathrm{~mL}$ of distilled water was added. The final mixture was dialyzed using a cellulose dialysis tubing (MWCO 3000) against deionized water for $48 \mathrm{~h}$, and then freeze-dried using a lyophilizer. After freeze-drying, the residue was redissolved in distilled water and filtered through a $0.45-\mu \mathrm{m}$ filter syringe. The liquid was then freeze-dried again and the formed product was characterized by proton NMR spectroscopy (Brucker, $600 \mathrm{MHz}$, Billerica, MA, USA) and MALDI-TOF mass spectrometer (AXIMA-Assurance, Shimadzu, Kyoto, Japan).

\subsection{Preparation of TPP-DSPE-PEG-Modified Liposomes Carrying Resveratrol (TLS (Res)) and DQA-DSPE-PEG-Modified Liposomes Carrying Resveratrol (DLS (Res))}

The TLS (Res) and DLS (Res) were prepared using a previously reported method with minor modifications [33]. The following lipids (total amount of $2 \mathrm{mg}$ ) were dissolved in chloroform: POPC:cholesterol:PEG-PE (7:3:0.15 in $\mu \mathrm{mol})$ and $100 \mu \mathrm{g}$ of resveratrol dissolved in ethanol was added to the lipid/chloroform solution. Then, PEG-PE $(0.15 \mu \mathrm{mol})$, TPP-DSPE-PEG $(0.15 \mu \mathrm{mol})$ or DQA-DSPE-PEG $(0.15 \mu \mathrm{mol})$ was added to obtain non-targeting liposomes carrying resveratrol (LS (Res)) and mitochondria-targeting liposomes carrying resveratrol (TLS (Res) or DLS (Res)), respectively. The organic solvents (chloroform and ethanol) were removed by vacuum evaporation, then the dried lipid film was mixed with $1 \mathrm{~mL}$ HBG buffer (10 mM HEPES, 5\% glucose, pH 7.4) and incubated at room temperature for $4 \mathrm{~h}$ with intermittent shaking. The lipid-contained suspension was extruded 11 times through polycarbonate membranes with a 100-nm pore size by a hand-held extruder (Avestin, Ottawa, Canada).

\subsection{Measurement of Size Distribution and Zeta Potential}

To measure the average size and surface charge of LS, TLS and DLS, each sample was diluted 1:100 in HBS (10 mM HEPES, $150 \mathrm{mM} \mathrm{NaCl}, \mathrm{pH}$ 7.4) to a total volume $1 \mathrm{~mL}$. Then dynamic light scattering (DLS) and electrophoretic light scattering (laser Doppler) analysis of LS, TLS and DLS were performed using a zeta potential and particle size analyzer (ELSZ-1000, Otsuka Electronics Co, Osaka, Japan). The LS (Res), TLS (Res) and DLS (Res) were passed over a Sephadex PD-10 column equilibrated with phosphate buffered saline $\left(137 \mathrm{mM} \mathrm{NaCl}, 2.7 \mathrm{mM} \mathrm{KCl}, 8 \mathrm{mM} \mathrm{Na}_{2} \mathrm{HPO}_{4}\right.$ and $2 \mathrm{mM} \mathrm{KH}_{2} \mathrm{PO}_{4}, \mathrm{PBS}_{\text {, }}$ $\mathrm{pH}$ 7.4) to remove the non-encapsulated resveratrol. 


\subsection{In Vitro Release Study}

In vitro drug release was investigated using previously reported methods with minor modifications [42]. The LS (Res) solution $(200 \mu \mathrm{L}$ of $100 \mu \mathrm{g} / \mathrm{mL}$ resveratrol in liposomes) was prepared and added to a GeBaFlex-tube with a molecular weight cut off of $8 \mathrm{kDa}$ (Gene Bio-Application Ltd., Yavne, Israel). The tubes contained with LS (Res) solution were immersed in $3 \mathrm{~mL}$ PBS (pH 7.4) and incubated at $37^{\circ} \mathrm{C}$ with rotation at 50 rounds per minute (rpm). Samples of the dissolution medium ( $3 \mathrm{~mL}$ ) were collected at various time points $(1,2,3,4,6,9,12,24$ and $48 \mathrm{~h}$ ), and replaced with $3 \mathrm{~mL}$ fresh medium at $37^{\circ} \mathrm{C}$. The amount of resveratrol released was assessed using LC/MS/MS analysis, and the samples were prepared by extracting twice with ethyl acetate, followed by drying of the organic phase under high vacuum. The dried residue was then suspended in $20 \mu \mathrm{L}$ of an acetonitrile and $0.1 \%$ formic acid 60:40 (v/v) mixture and sonicated for $10 \mathrm{~min}$. Finally, a $10 \mu \mathrm{L}$ aliquot was analyzed using LC/MS/MS, as described below.

\subsection{In Vitro Cytotoxicity Assay}

The cytotoxicity of the LS, TLS, DLS, free Res, LS (Res), TLS (Res) and DLS (Res) was assessed using the cell viability assay. Briefly, B16F10 were seeded in 96-well plates at a density of $1 \times 10^{4}$ cells/well and incubated overnight at optimal condition. The cells were treated by replacing the medium with fresh serum-free medium containing a range of concentrations of LS, TLS, DLS, free Res, LS (Res), TLS (Res) and DLS (Res). Following incubation for $24 \mathrm{~h}$ at $37^{\circ} \mathrm{C}$, the cells were washed twice with PBS, then incubated with serum-free medium containing water-soluble tetrazolium (WST) solution (Ez-Cytox Cell Viability Assay Kit, DoGen, Korea) for $30 \mathrm{~min}$ at $37^{\circ} \mathrm{C}$ in the dark. The absorbance was measured at $480 \mathrm{~nm}$ using a microplate reader (Epoch, BioTek Instruments, Winooski, VT, USA).

\subsection{In Vitro Cellular Uptake Analysis by Laser Scanning Confocal Microscopy}

The B16F10 murine melanoma cells were maintained in Dulbecco's Modified Eagle's medium (DMEM) supplemented with 10\% fetal bovine serum (complete DMEM medium) in a humidified incubator under $5 \% \mathrm{CO}_{2}$. The cells at a density of $1 \times 10^{5}$ cells were seeded on coverslips $(12 \mathrm{~mm}$, Fisher Scientific) and incubated for $24 \mathrm{~h}$ at $37^{\circ} \mathrm{C}$ and in a $5 \% \mathrm{CO}_{2}$ atmosphere. The LS, TLS and DLS, containing rhodamine-labeled PE (Rh-PE), were diluted to a final concentration of $100 \mu \mathrm{g} / \mathrm{mL}$ in serum-free medium and treated to the cells. After 1-h incubation, the cells were stained with 4',6-diamidino-2-phenylindole (DAPI) and fixed using 2\% (w/v) paraformaldehyde in PBS. The coverslips were mounted with a mounting medium (Fluoromount, Sigma-Aldrich) and the fluorescent images of cells on the coverslip were analyzed using a laser scanning confocal microscope (LSCM, A1Plus, Nikon, Tokyo, Japan).

\subsection{In Vitro Quantification of Mitochondrial Accumulation of Resveratrol by LC-MS/MS}

\subsubsection{Treatment of Liposomes and Cell Fractionation}

B16F10 cells were grown with complete DMEM medium in a 100-mm dish overnight to $80 \%$ confluence. Free Res, LS (Res), DLS (Res) and TLS (Res) were diluted with serum free media to total $5 \mathrm{~mL}$, corresponding to $20 \mu \mathrm{g}$ resveratrol, and treated to the cells. After $10 \mathrm{~min}, 30 \mathrm{~min}$ and $1 \mathrm{~h}$ of incubation at $37^{\circ} \mathrm{C}$, the cells were harvested, collected by centrifugation and two times washed with PBS. To separate mitochondria in the cells, cell fractionation was performed on the cell pellet using the Mitochondria/Cytosol Fractionation kit (Biovision, USA). Briefly, $1 \mathrm{~mL}$ of $1 \times$ cytosol extraction buffer mix containing DTT and protease inhibitors was added to the pellet (according to the manufacturer's protocol) and mixed and incubated on ice for $10 \mathrm{~min}$. Next, the cells were homogenized on ice using a glass tissue grinder, then the homogenate was centrifuged at $3000 \mathrm{rpm}$ for $10 \mathrm{~min}$ at $4{ }^{\circ} \mathrm{C}$. The supernatant was replaced to the new Ep tube and then centrifuged at 13,000 rpm for $30 \mathrm{~min}$ at $4{ }^{\circ} \mathrm{C}$. The supernatant in this step contains the cytosol fraction. Then the pellet was resuspended in the mitochondrial extraction buffer mix, containing DTT and protease inhibitors. The mitochondrial and 
cytosolic fractions were used to measure the resveratrol taken-up by the mitochondria. Ethylacetate extraction was performed to collect the resveratrol.

\subsubsection{LC-MS/MS Conditions}

The LC-MS/MS system consists of an Agilent LC 1100 series (Agilent Technologies, CA, USA) binary pump, a vacuum degeneration unit and an auto-sampler system connected to a 6490 triple quadrupole MS equipped with an Agilent jet stream technology electrospray ionization (ESI) source. Chromatographic separation was performed by an analysis Sepax BR-C18 (5 $\mu \mathrm{m}, 120 \AA 1.0 \times 100 \mathrm{~mm})$ column. The maintaining temperature of column was set at $30^{\circ} \mathrm{C}$. The temperature of the auto-sampler was set at $4{ }^{\circ} \mathrm{C}$. Of the sample solution $2 \mu \mathrm{L}$ was injected and the analytes were eluted under the isocratic condition with acetonitrile and $0.1 \%$ formic acid in water $(60 \%: 40 \%, v / v)$ pumped at a constant flow of $0.10 \mathrm{~mL} / \mathrm{min}$. To detection of the resveratrol in the analytes, the MS/MS system was performed under negative ESI and the multiple reactions monitoring (MRM) mode. The MS operational parameters were: Argon as a collision gas; capillary voltage at $5 \mathrm{kV}$; gas temperature at $225^{\circ} \mathrm{C}$; gas flow $14.1 \mathrm{I} / \mathrm{min}$; nebulizing gas at $40 \mathrm{psi}$; collision energies of 18 for resveratrol and the precursor to product ion transitions of $184.8-226.9 \mathrm{~m} / \mathrm{z}$ for resveratrol.

\subsection{In Vitro ROS Production}

The B16F10 cells were seeded on the six-well plates at a density of $4 \times 10^{5}$ cells/well. Then the cells were treated with serum-free culture medium (as the control), free Res, LS (Res), TLS (Res) and DLS (Res), respectively. The final concentration of resveratrol in each treatment sample was $4 \mu \mathrm{g} / \mathrm{mL}$. After $12 \mathrm{~h}$, the cells were collected, suspended and incubated with DCFH-DA $(10 \mu \mathrm{M})$ at $37^{\circ} \mathrm{C}$ for $20 \mathrm{~min}$. After two washes with cold PBS, the DCF fluorescence was determined using a fluorescence-activated cell sorter (FACS).

\subsection{In Vitro Mitochondrial Depolarization}

The JC-1 was used for the measurement of mitochondrial membrane potential $(\Delta \Psi \mathrm{m})$ due to the ability to shift of the cationic lipophilic fluorochrome JC-1 from red to green. The B16F10 cells were seeded on the six-well plates at a density of $4 \times 10^{5}$ cells/well and treated with serum-free culture medium (as control), free Res, LS (Res), TLS (Res) and DLS (Res; $4 \mu \mathrm{g} / \mathrm{mL}$ as final concentration of resveratrol) for $12 \mathrm{~h}$. The cells were harvested, suspended and incubated with the JC-1 dye $(1 \mu \mathrm{g} / \mathrm{mL})$ in the dark at $37^{\circ} \mathrm{C}$ for $10 \mathrm{~min}$. The cells were washed with PBS and fluorescence intensity from cells was measured by flow cytometry.

\subsection{Statistical Analysis}

All of the studies were performed in triplicate. The results were expressed as mean \pm standard error of the mean (S.E.M.). The statistical significance of the data was analyzed by Student's $t$-test and analysis of variance (ANOVA) with Bonferroni's post-hoc test. A value of $p<0.05$ was considered to be statistically significant.

\section{Results and Discussion}

\subsection{Synthesis of TPP-DSPE-PEG and DQA-DSPE-PEG Conjugate}

For the targeted delivery of resveratrol to the mitochondria in cancer cells, we proposed liposomes, surface-modified with TPP or DQA. To achieve this, 4-carboxybutyl triphenylphosphonium bromide- polyethylene glycol-distearoylphosphatidylethanolamine (TPP-DSPE-PEG) and dequaliniumpolyethylene glycol-distearoylphosphatidylethanolamine (DQA-DSPE-PEG) were synthesized as mitochondriotropic molecules. Their synthesis scheme is presented in Figure 2.

TPP-DSPE-PEG formation was confirmed by the proton NMR spectrum. The appearance of signals at 7.46-7.76 ppm was attributed to the presence of $\mathrm{CH}=\mathrm{CH}$ and the phenyl ring of TPP and 
signals at 2.66, 2.0 and $1.6 \mathrm{ppm}$ were attributable to the methylene group of the carboxy butyl linker. Signals at 6 and $6.5 \mathrm{ppm}$ appeared due to the presence of the $\mathrm{NH}$ group in the conjugate. In addition, the major signals of DSPE-PEG (at $3.7 \mathrm{ppm}$ for $-\mathrm{CH}_{2}-\mathrm{CH}_{2}-\mathrm{O}$ of PEG and at 1-3.5 ppm and $0.85 \mathrm{ppm}$ for methylene and the methyl groups in the lipid chain, respectively) in the proton NMR spectrum also indicated the formation of the conjugate (Figure 3A,B). The MALDI-TOF spectrum showed a peak at $3133.5 \mathrm{~m} / \mathrm{z}$ that was assigned to TPP-DSPE-PEG $\left(\mathrm{M}-\left[\mathrm{Br}^{-}\right]+\left[2 \mathrm{H}^{+}\right]\right.$; Figure $\left.3 \mathrm{C}\right)$. The MALDI-TOF assay results also clearly confirmed the graft reaction of TPP to DSPE-PEG.

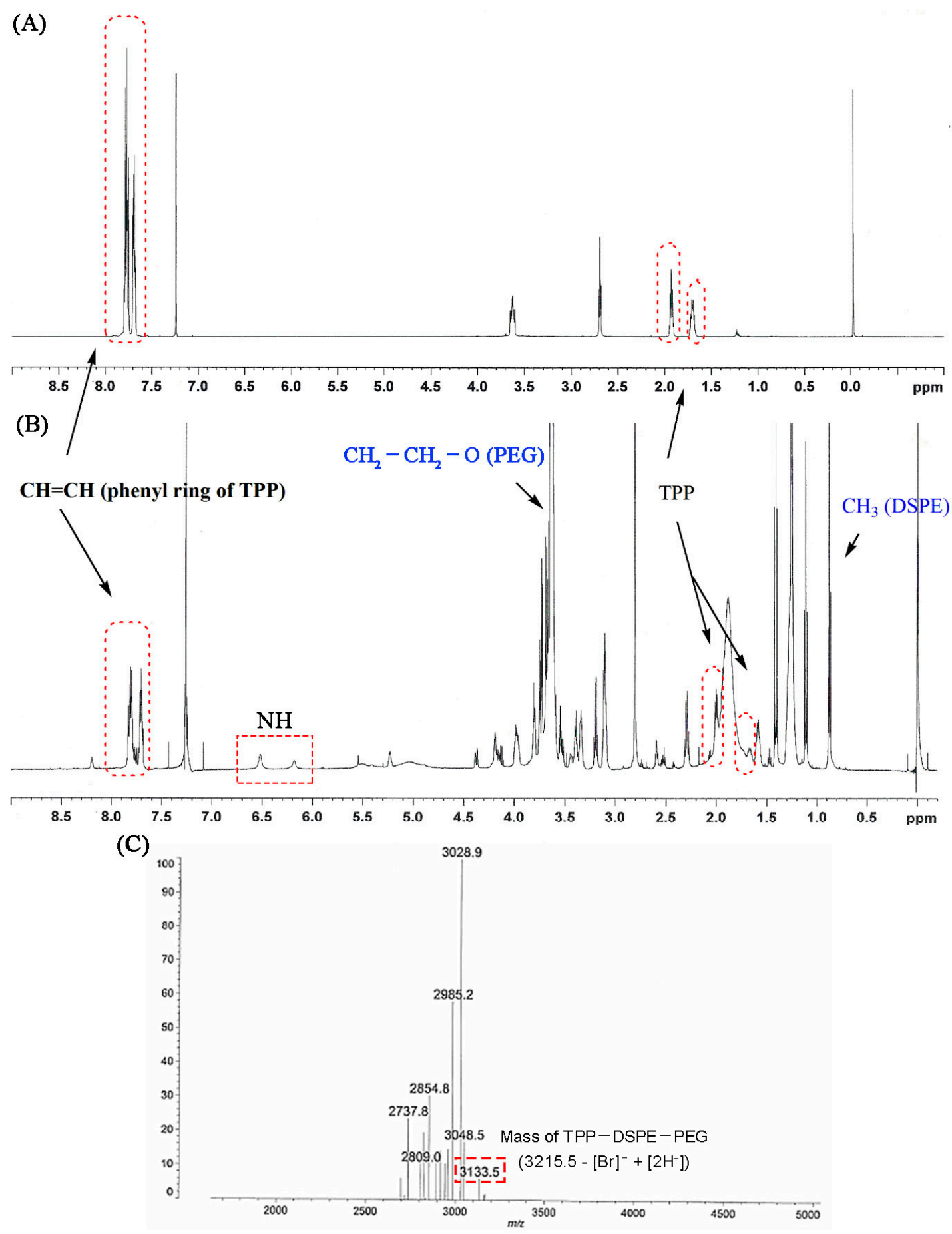

Figure 3. Proton NMR spectra of carboxybutyl triphenylphosphonium bromide (TPP) (A) and TPP-DSPE-PEG conjugate (B). (C) MALDI-TOF mass of TPP-DSPE-PEG. 
The formation of DQA-DSPE-PEG was confirmed by the proton NMR spectrum. The appearance of signals at 7.7-9.0 ppm and $4.4 \mathrm{ppm}$ were attributed to the presence of $\mathrm{CH}=\mathrm{CH}$ in the aromatic ring and amine group of DQA, respectively, and signals at 1.2-3.5 ppm were attributable to the methylene group of the aliphatic chain between the two quinolines. Upon formation of the conjugate and the consequent creation of a $\mathrm{NH}$ group, a new signal at $6 \mathrm{ppm}$ appeared. In addition, the major signals of DSPE-PEG (at $3.5 \mathrm{ppm}$ for $-\mathrm{CH}_{2}-\mathrm{CH}_{2}-\mathrm{O}$ of PEG, at 1-3.7 ppm and $0.8 \mathrm{ppm}$ for methylene and the methyl groups in the lipid chain, respectively) in the proton NMR spectrum also indicated the formation of the conjugate (Figure 4A,B). MALDI-TOF spectrum showed a peak at $3342.6 \mathrm{~m} / \mathrm{z}$ that was assigned to DQA-DSPE-PEG (M-[NH 2$]$; Figure $4 \mathrm{C})$. The MALDI-TOF assay results also clearly confirmed the graft reaction of DQA to DSPE-PEG.
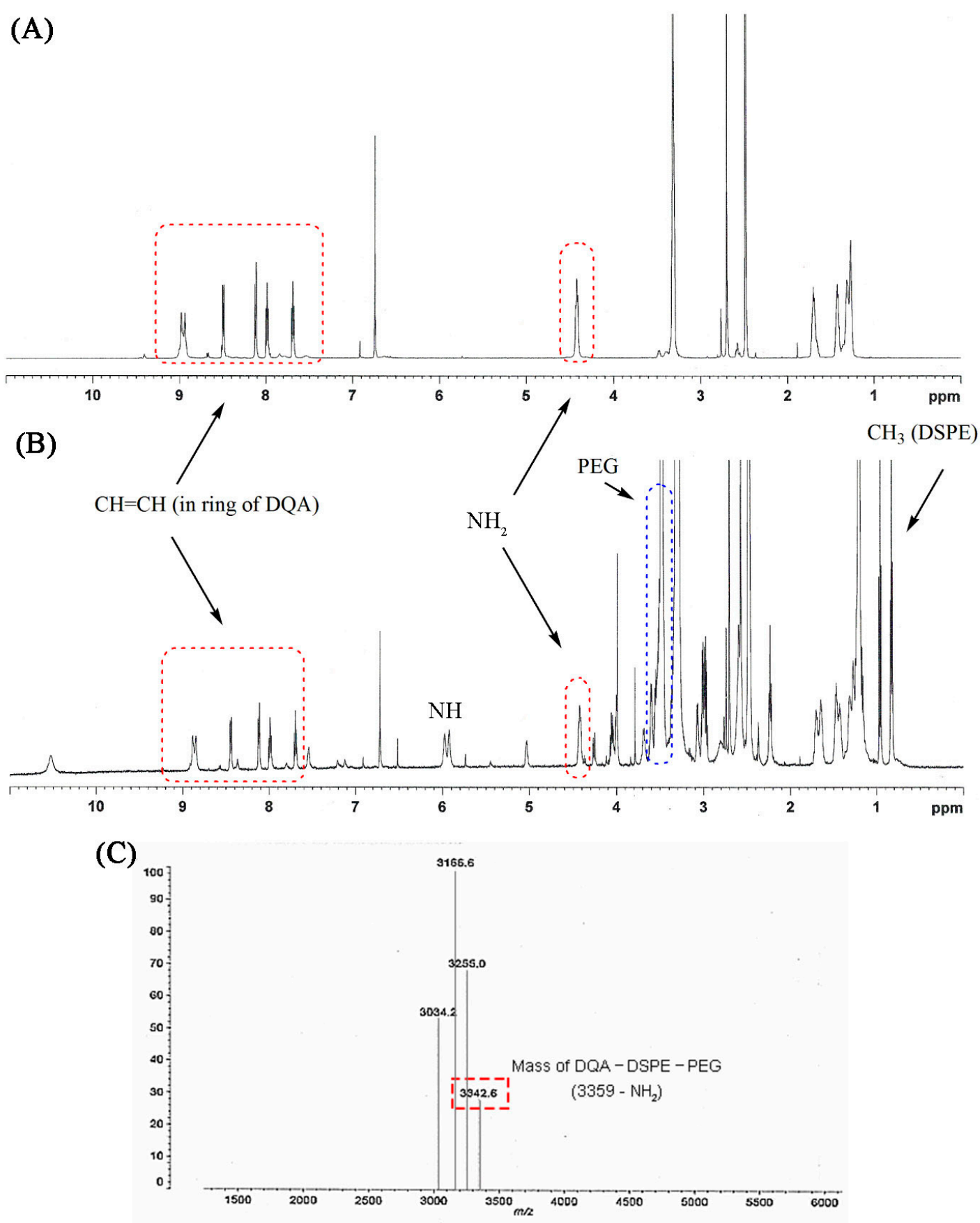

Figure 4. Proton NMR spectra of dequalinium (DQA) (A) and DQA-DSPE-PEG conjugate (B). (C) MALDI-TOF mass of DQA-DSPE-PEG. 


\subsection{Characterization of TLS (Res) and DLS (Res)}

Liposome-based drug delivery systems have been proposed for the delivery of hydrophobic as well as hydrophilic therapeutic molecules and showed high biocompatibility with low toxicity [38]. Considering these benefits, a liposome carrier system was developed in this study to protect and stabilize resveratrol. In addition, the constructed resveratrol-containing liposomes exposed the molecules TPP or DQA on their surface to target specifically the mitochondria. In this study, the mitochondriotropic liposomes were constructed with rational lipid composition and thin-film hydration followed by the extrusion method according to previously published method [33,43], the amount of mitochondrial targeting ligand was decided as the amount to exert a targeting effect $[2,44,45]$. Table 1 shows the average particle sizes, polydispersity index (PDI) and zeta potentials of LS (Res), TLS (Res) and DLS (Res). Results indicated that the mean hydrodynamic diameter of the liposomes was approximately $120 \mathrm{~nm}$ with a narrow size distribution (PDI < 0.3). The narrow and uniform size distributions of LS (Res), TLS (Res) and DLS (Res) were obtained after membrane extrusion. The determined surface charges are $-1.68 \pm 0.31 \mathrm{mV}, 10.46 \pm 0.43 \mathrm{mV}$ and $13.79 \pm 0.31 \mathrm{mV}$ for LS (Res), TLS (Res) and DLS (Res), respectively (Table 1). TLS (Res) and DLS (Res) showed a positive surface charge, whereas LS (Res) displayed a neutral surface charge, confirming the presence of the highly positively charged TPP or DQA moieties on the liposomes, and demonstrating that they contributed to the change of the liposome's surface charge. It was reported that the loading capacity of extruded liposomes carrying resveratrol showed more than $5 \%$ and the encapsulation efficiencies of resveratrol in liposomal carriers were found to be more than $90 \%$ [2,46-48]. Based on the references, we prepared the liposomes with a lipids/resveratrol ratio of 20:1 (w/w). The diameter of approximately $100 \mathrm{~nm}$ of TLS (Res) and DLS (Res) should allow accumulation into tumor tissue by the enhanced permeability and retention (EPR) effect [35].

Table 1. Size, polydispersity index (PDI) and zeta potential of LS (Res), TLS (Res) and DLS (Res). Mean \pm S.E.M, $n=5$.

\begin{tabular}{cccc}
\hline Formulations & Size Distribution $(\mathbf{n m})$ & PDI & Zeta Potential $(\mathbf{m V})$ \\
\hline LS (Res) & $128.10 \pm 6.77$ & $0.25 \pm 0.12$ & $-1.68 \pm 0.31$ \\
TLS (Res) & $115.50 \pm 3.99$ & $0.22 \pm 0.02$ & $10.46 \pm 0.43$ \\
DLS (Res) & $121.18 \pm 3.65$ & $0.28 \pm 0.02$ & $13.79 \pm 0.31$ \\
\hline
\end{tabular}

To evaluate whether resveratrol was released by the liposomes, the drug release rate was measured at $37^{\circ} \mathrm{C}$ in PBS (pH 7.4). Figure 5 shows the cumulative release profile of resveratrol in percentage. The resveratrol-loaded liposomes showed an initial relatively faster release $(31.11 \% \pm 4.15 \%)$ in PBS ( $\mathrm{pH} 7.4$ ) within $4 \mathrm{~h}$, followed by a sustained release pattern $(62.12 \% \pm 10.25 \%)$ up to $48 \mathrm{~h}$, whereas free resveratrol showed a release burst with ca. a 100\% release at $2 \mathrm{~h}$. The liposomal system demonstrated a sustained release profile, useful for the sustained delivery of resveratrol.

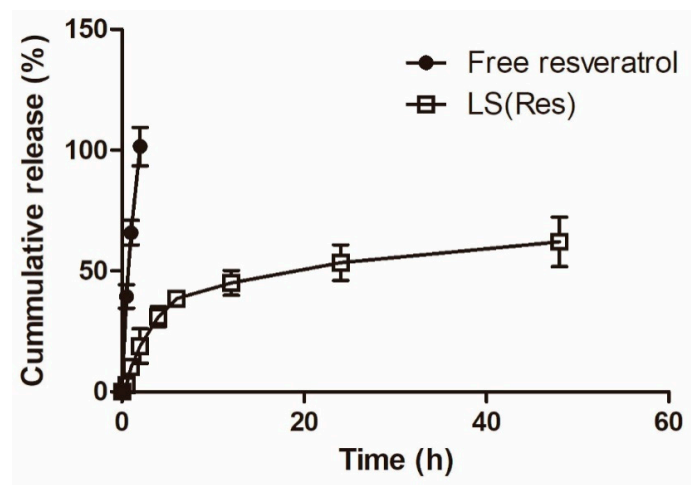

Figure 5. Percentage of cumulative release of free resveratrol and LS (Res) in PBS (pH 7.4). Mean \pm S.E.M, $n=3$. 


\subsection{In Vitro Cellular Cytotoxicity}

Figure 6A shows the cytotoxicity of the non-targeting (LS) and mitochondria-targeting liposomes (TLS and DLS) without resveratrol in B16F10 cells. Cell viability showed no significant differences among cells treated with LS, TLS and DLS for $24 \mathrm{~h}$. The average cell viability showed a higher than $90 \%$ up to the liposomes concentration of $500 \mu \mathrm{g} / \mathrm{mL}$. This result indicated that mitochondriotropic liposomes did not seriously damage cells, demonstrating that the liposomes itself did not contribute to the cellular toxicity.
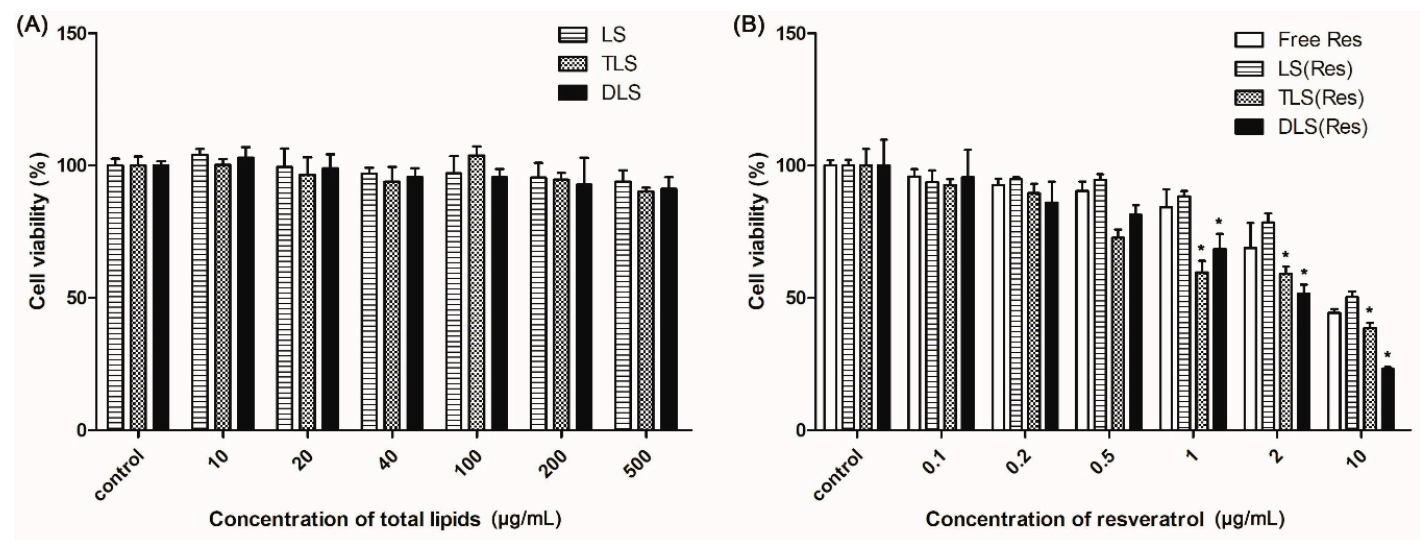

Figure 6. In vitro viability of B16F10 cells after applying the liposomes (A) non-carrying resveratrol and (B) carrying resveratrol at 24 h. Mean \pm S.E.M, $n=4 .{ }^{*}$ indicates a statistical difference from the LS (Res), $p<0.05$.

To further evaluate the cytotoxicity of the mitochondria-targeting liposomes carrying resveratrol, an MTT assay was carried out with different concentrations of the liposomes. As shown in Figure 6B, the free Res, LS (Res), TLS (Res) and DLS (Res) showed dose-dependent cytotoxicity against B16F10 cells. In particular, the mitochondriotropic liposomes carrying resveratrol (TLS (Res) and DLS (Res)) showed the lower viability than free Res and LS (Res), indicating that the mitochondria-targeting liposomes improves the cytotoxicity efficacy of resveratrol in cancer cells.

\subsection{In Vitro Cellular Uptake and Mitochondrial Targeting}

Figure 7 represents the laser scanning confocal microscopic images of the cellular uptake and intracellular localization of liposomes in B16F10 cells. To observe this, the non-targeting (LS) and mitochondria-targeting liposomes (TLS and DLS) without resveratrol were labeled with rhodamine-labeled PE (red fluorescence) and the mitochondria were stained by MitoTracker green (green fluorescence). The red fluorescence intensity of TLS and DLS in the B16F10 cells after $1 \mathrm{~h}$ of incubation was stronger than that of LS, indicating higher cellular uptake of TLS and DLS into B16F10 cells compared to LS. The positive surface charge of TLS and DLS may contribute to an easier attachment to and uptake into the cells, as they have a negative surface charge due to the phospholipid bilayer composition [49]. Additionally, a bright yellow fluorescence, which is the result of the overlay of red and green fluorescence, was observed for TLS and DLS, indicating that TLS and DLS were localized on the mitochondria after internalization by the cells. In the case of LS, however, their mitochondrial localization was reduced compared to TLS and DLS. These results demonstrate that mitochondria-targeting liposomes labeled with TPP or DQA are able to accumulate selectively in the mitochondria. 


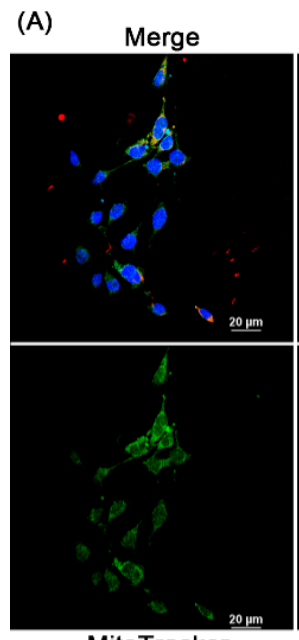

MitoTracker
DAPI

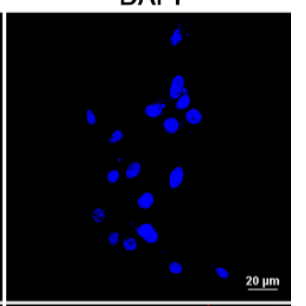

$20 \mu \mathrm{m}$

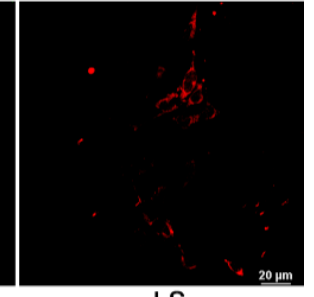

LS
(B)

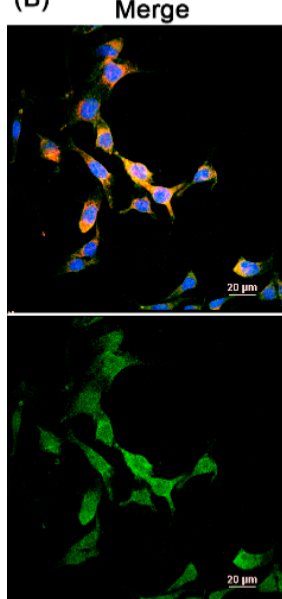

MitoTracker
DAPI

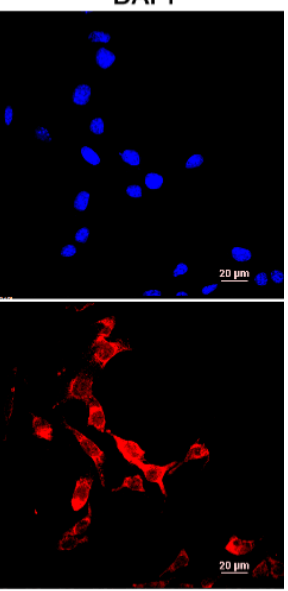

TLS

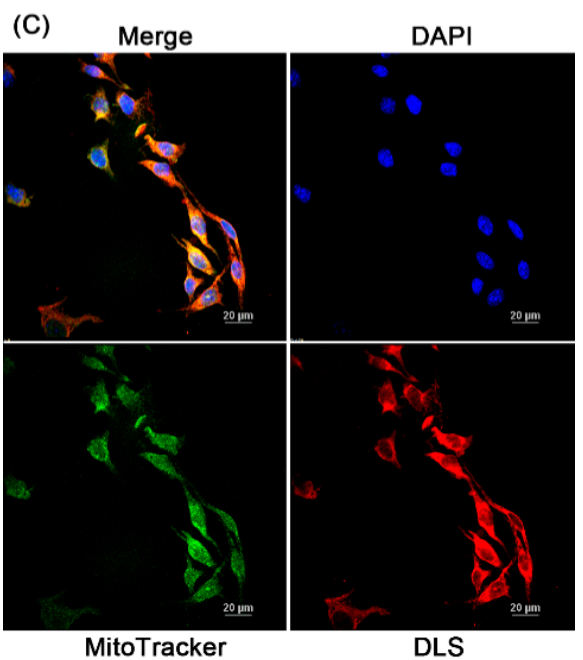

Figure 7. Cellular uptake of the non-targeting liposomes without resveratrol (LS) and mitochondrialtargeting liposomes without resveratrol (TLS and DLS) in B16F10 cells. Laser scanning confocal microscopy (LSCM) images after a $1 \mathrm{~h}$ of incubation with LS (A), TLS (B) and DLS, and (C) red, rhodamine-labeled liposome; green, MitoTracker; blue, 4',6-diamidino-2-phenylindole (DAPI).

Furthermore, to quantify the mitochondrial accumulation of resveratrol delivered by mitochondriatargeting liposomes, mitochondrial and cytosol fractionation was performed. The amount of mitochondrial accumulation was quantified using LC-MS/MS and the percentage ratio was calculated based on total uptake amount of resveratrol in each treated group. At $1 \mathrm{~h}$ post-incubation, significantly higher concentrations of resveratrol were found in the cells treated with TLS (Res; $785.3 \pm 82.7 \mathrm{ng} / \mathrm{mL}$ ) and DLS (Res; $927.1 \pm 101.2 \mathrm{ng} / \mathrm{mL}$ ) as compared to those treated with LS (Res; $418.0 \pm 31.9 \mathrm{ng} / \mathrm{mL}$ ) and free resveratrol (227.5 $\pm 58.3 \mathrm{ng} / \mathrm{mL}$; data not shown). As shown in Figure 8, the mitochondrial resveratrol percentage ratio of TLS (Res) and DLS (Res) was 2.4- and 3.1-fold higher than that of LS (Res) in B16F10. In addition, the mitochondrial resveratrol percentage ratio of TLS (Res) and DLS (Res) was 5.1- and 6.6-fold higher than that of free resveratrol in B16F10. These results indicate that TLS (Res) and DLS (Res) were selectively accumulated in the mitochondria by the TPP- and DQA-moieties on the surface of liposomes after internalization by the cells. 


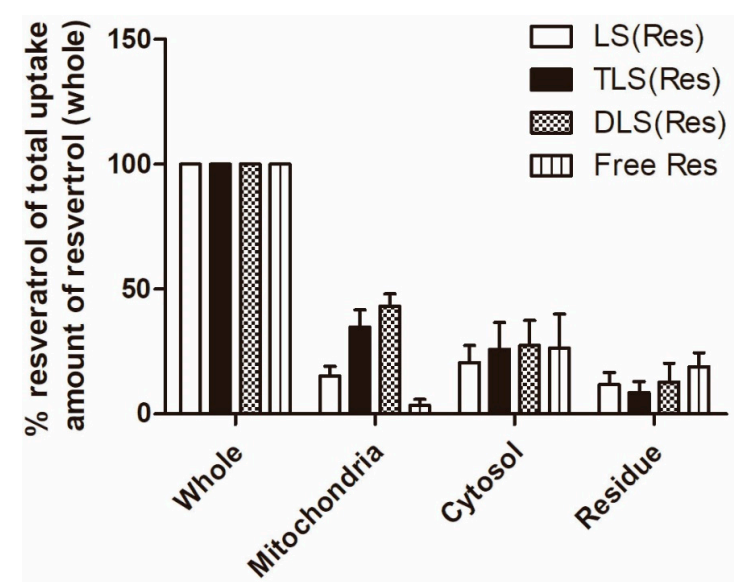

Figure 8. Intracellular uptake of LS (Res), TLS (Res), DLS (Res) and free resveratrol by B16F10 cells after $1 \mathrm{~h}$ of incubation. The data represent the mean \pm S.E.M $(n=3)$.

\subsection{In Vitro ROS Production}

To determine the effect of resveratrol delivered by mitochondrial-targeting liposomes, we evaluated the ROS generation in the B16F10 cells treated with the free resveratrol, LS (Res), TLS (Res) and DLS (Res) after $12 \mathrm{~h}$ of incubation in the presence of the DCFH-DA reagent using FACS. The DCFH-DA fluorescent dye was used as it is transformed into 2,7-dichlorofluorescein upon ROS generation. The positive control was used as a standard of occurring change in the ROS production. As shown in Figure 9, fluorescence intensity of LS (Res), TLS (Res) and DLS (Res) increased more than that of free resveratrol in B16F10 cells after $12 \mathrm{~h}$ incubation, indicating that liposome formulations generated greater intracellular ROS levels compared to free resveratrol. The mean of fluorescence intensity in each group was calculated as TLS (Res; $1024.5 \pm 12.3$ ), DLS (Res; $1799.1 \pm 14.9$ ), LS (Res; $842.2 \pm 7.9$ ), free resveratrol (705.3 \pm 17.1$)$ and positive control (619.3 \pm 25.1$)$. TLS (Res) and DLS (Res) generated 1.2and 2.1-fold greater ROS levels than LS (Res) did. In contrast, no ROS was generated in the control cells without drug treatment. ROS production in the mitochondria is closely associated with cell damage, such as inflammation, oxidative stress and cell organelle disruption [50-52].

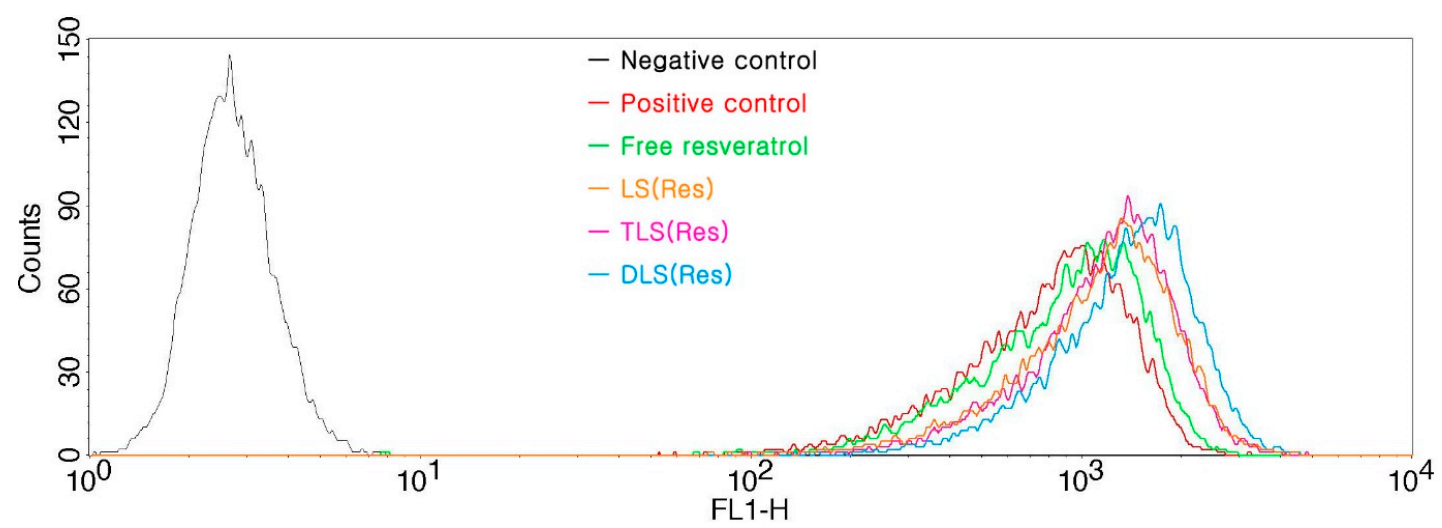

Figure 9. Reactive oxygen species (ROS) production measured with DCFH-DA in B16F10 cells treated with free resveratrol, LS (Res), TLS (Res) and DLS (Res) after $12 \mathrm{~h}$ of incubation. Production of ROS was measured in fluorescence at excitation and emission wavelengths of 485 and $528 \mathrm{~nm}$, respectively.

\subsection{In Vitro Mitochondrial Depolarization}

To evaluate the mitochondrial depolarization, flow cytometry studies with JC-1 dye staining were performed in B16F10 cells treated with free resveratrol, LS (Res), TLS (Res) and DLS (Res) for $12 \mathrm{~h}$. A switch from the red to green fluorescence of the JC-1 dye indicated depolarization. The negative 
control and positive control indicate cells stained without and with JC-1, respectively. The two control cells were incubated in only serum free media for $12 \mathrm{~h}$. The positive control presents only JC-1-stained the cells without any treatments. The degree of mitochondria depolarization was evaluated by moved events from the upper right to lower right section of the diagrams. As shown in Figure 10, the percentage of mitochondrial membrane depolarization was $7.95 \% \pm 1.32 \%, 13.41 \% \pm 2.95 \%, 24.78 \% \pm 4.19 \%$ and $32.45 \% \pm 3.07 \%$ in the free resveratrol, LS (Res), TLS (Res) and DLS (Res)-treated cells, respectively. The mitochondrial membrane potential $\left(\Delta \Psi_{\mathrm{m}}\right)$ of the TLS (Res) and DLS (Res)-treated cells was 1.8- and 2.4- fold higher than that of the LS (Res)-treated cells. The TLS (Res) and DLS (Res)-treated cells had the biggest dissipation of $\Delta \Psi_{\mathrm{m}}$, indicating that the mitochondria-specific targeting of resveratrol, by TPP and DQA moieties on the liposomes' surface, triggered the increased dissipation of $\Delta \Psi_{\mathrm{m}}$. It was reported that ROS production can be triggered by mitochondria dysfunction [53] and excess levels of ROS in the cells cause damage to cellular organelles, which can lead to activation of apoptosis $[54,55]$. The mitochondrial membrane depolarization is the result of mitochondrial dysfunction, which leads to cell death via initiation of the apoptotic pathway.

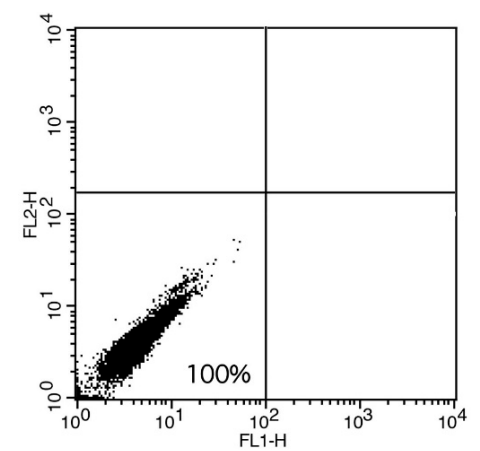

Negative control

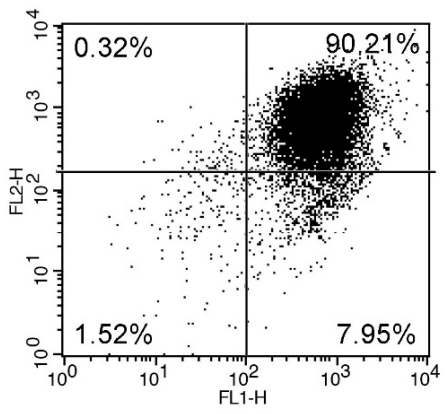

Free resveratrol

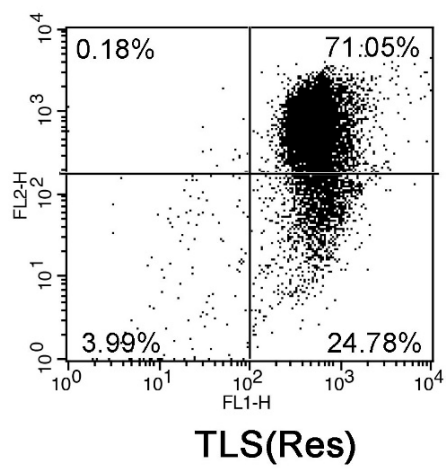

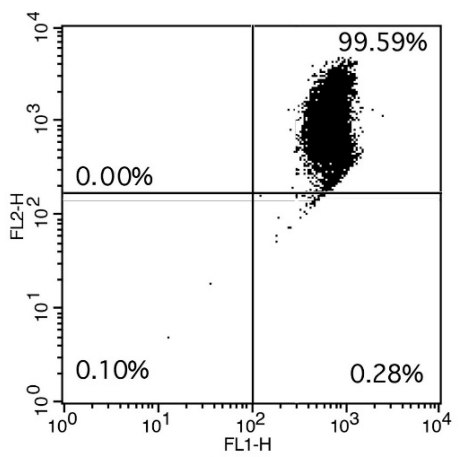

Positive control
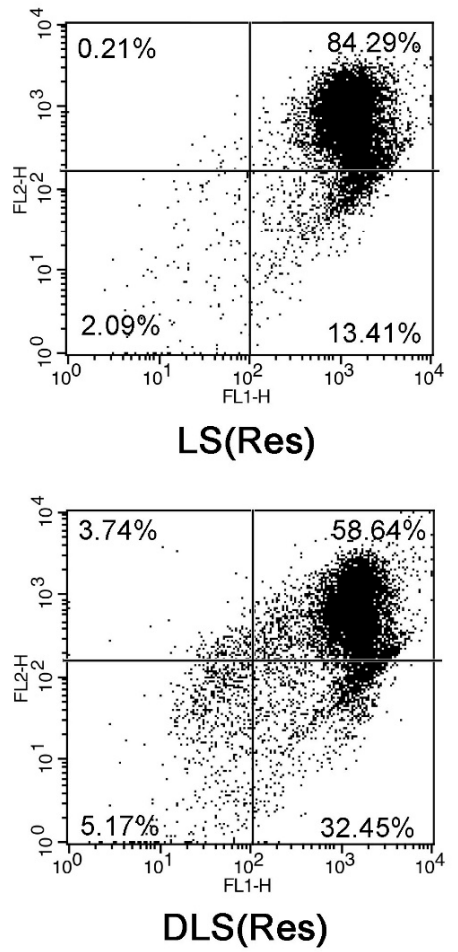

Figure 10. Mitochondrial depolarization of free resveratrol, LS (Res), TLS (Res) and DLS (Res) after $12 \mathrm{~h}$ incubation using flow cytometry. 


\section{Conclusions}

In this study, TPP-DSPE-PEG and DQA-DSPE-PEG were synthesized as mitochondriotropic molecules with the aim of enhancing both the mitochondrial targeting of nanoparticle systems and the anticancer efficacy of the resveratrol. The conjugates were characterized using physical methods including NMR and MS. The mitochondria-targeting liposomes carrying resveratrol were constructed by modifying the TPP-DSPE-PEG or DQA-DSPE-PEG on the surface of liposomes. TLS (Res) and DLS (Res) showed superior in vitro behavior in the B16F10 cells, including increased accumulation in mitochondria, anticancer efficacy, ROS generation and mitochondrial depolarization, compared to that of LS (Res). Since the selectivity of liposomes for cancer cells can be improved by adding a cancer-targeting moiety on their surface, the mitochondria-targeting liposomes carrying resveratrol provide a potential strategy for cancer treatment by mitochondrial targeting delivery of therapeutics and stimulation the mitochondrial signaling pathway.

Author Contributions: Y.T.K.: Conceptualization, data interpretation, supervision; J.H.K.: Preparation of formulations, in vitro experiments, writing-original daft preparation and review/editing.

Funding: This research was supported by the Basic Science Research Program and the Pioneer Research Center Program of the National Research Foundation of Korea (NRF) grant funded by the Ministry of Education, Science and Technology (NRF-2017R1A2B4002743 and NRF 2014M3C1A3054153). This research was also supported by the Gachon University research fund of 2018 (GCU-2018-0322).

Conflicts of Interest: The authors declare no conflict of interest.

\section{References}

1. Javadov, S.; Kuznetsov, A.V. Mitochondria: The cell powerhouse and nexus of stress. Front. Physiol. 2013, 4, 207. [CrossRef] [PubMed]

2. Wang, X.X.; Li, Y.B.; Yao, H.J.; Ju, R.J.; Zhang, Y.; Li, R.J.; Yu, Y.; Zhang, L.; Lu, W.L. The use of mitochondrial targeting resveratrol liposomes modified with a dequalinium polyethylene glycol-distearoylphosphatidyl ethanolamine conjugate to induce apoptosis in resistant lung cancer cells. Biomaterials 2011, 32, 5673-5687. [CrossRef]

3. Mandal, S.; Lindgren, A.G.; Srivastava, A.S.; Clark, A.T.; Banerjee, U. Mitochondrial function controls proliferation and early differentiation potential of embryonic stem cells. Stem Cells 2011, 29, 486-495. [CrossRef] [PubMed]

4. Copeland, W.C.; Wachsman, J.T.; Johnson, F.M.; Penta, J.S. Mitochondrial DNA alterations in cancer. Cancer Investig. 2002, 20, 557-569. [CrossRef]

5. Chihara, N.; Amo, T.; Tokunaga, A.; Yuzuriha, R.; Wolf, A.M.; Asoh, S.; Suzuki, H.; Uchida, E.; Ohta, S. Mitochondrial DNA alterations in colorectal cancer cell lines. J. Nippon Med Sch. Nippon Ika Daigaku Zasshi 2011, 78, 13-21. [CrossRef] [PubMed]

6. Tong, B.C.; Ha, P.K.; Dhir, K.; Xing, M.; Westra, W.H.; Sidransky, D.; Califano, J.A. Mitochondrial DNA alterations in thyroid cancer. J. Surg. Oncol. 2003, 82, 170-173. [CrossRef]

7. Lu, J.; Tan, M.; Cai, Q. The warburg effect in tumor progression: Mitochondrial oxidative metabolism as an anti-metastasis mechanism. Cancer Lett. 2015, 356, 156-164. [CrossRef]

8. Porporato, P.E.; Filigheddu, N.; Pedro, J.M.B.; Kroemer, G.; Galluzzi, L. Mitochondrial metabolism and cancer. Cell Res. 2018, 28, 265-280. [CrossRef]

9. Kalyanaraman, B.; Cheng, G.; Hardy, M.; Ouari, O.; Lopez, M.; Joseph, J.; Zielonka, J.; Dwinell, M.B. Corrigendum to 'a review of the basics of mitochondrial bioenergetics, metabolism, and related signaling pathways in cancer cells: Therapeutic targeting of tumor mitochondria with lipophilic cationic compounds' [redox 14c (2017) 316-327]. Redox Biol. 2018, 16, 426-427. [CrossRef]

10. Peng, Y.B.; Zhao, Z.L.; Liu, T.; Xie, G.J.; Jin, C.; Deng, T.G.; Sun, Y.; Li, X.; Hu, X.X.; Zhang, X.B.; et al. A multi-mitochondrial anticancer agent that selectively kills cancer cells and overcomes drug resistance. Chem. Med. Chem. 2017, 12, 250-256. [CrossRef]

11. Keibler, M.A.; Wasylenko, T.M.; Kelleher, J.K.; Iliopoulos, O.; Vander Heiden, M.G.; Stephanopoulos, G. Metabolic requirements for cancer cell proliferation. Cancer Metab. 2016, 4, 16. [CrossRef] [PubMed] 
12. Yamada, Y.; Harashima, H. Targeting mitochondria: Innovation from mitochondrial drug delivery system (dds) to mitochondrial medicine. Yakugaku Zasshi J. Pharm. Soc. Jpn. 2012, 132, 1111-1118. [CrossRef] [PubMed]

13. Zhong, H.; Xiao, M.; Zarkovic, K.; Zhu, M.; Sa, R.; Lu, J.; Tao, Y.; Chen, Q.; Xia, L.; Cheng, S.; et al. Mitochondrial control of apoptosis through modulation of cardiolipin oxidation in hepatocellular carcinoma: A novel link between oxidative stress and cancer. Free Radic. Biol. Med. 2017, 102, 67-76. [CrossRef] [PubMed]

14. Fernald, K.; Kurokawa, M. Evading apoptosis in cancer. Trends Cell Biol. 2013, 23, 620-633. [CrossRef] [PubMed]

15. Wei, Y.; Zhou, F.; Zhang, D.; Chen, Q.; Xing, D. A graphene oxide based smart drug delivery system for tumor mitochondria-targeting photodynamic therapy. Nanoscale 2016, 8, 3530-3538. [CrossRef] [PubMed]

16. Chen, Z.; Kang, X.; Wu, Y.; Xiao, H.; Cai, X.; Sheng, S.; Wang, X.; Chen, S. A mitochondria targeting artesunate prodrug-loaded nanoparticle exerting anticancer activity via iron-mediated generation of the reactive oxygen species. Chem. Commun. 2019, 55, 4781-4784. [CrossRef]

17. Xie, C.; Chang, J.; Hao, X.D.; Yu, J.M.; Liu, H.R.; Sun, X. Mitochondrial-targeted prodrug cancer therapy using a rhodamine b labeled fluorinated docetaxel. Eur. J. Pharm. Biopharm. 2013, 85, 541-549. [CrossRef] [PubMed]

18. Zhang, X.Y.; Zhang, P.Y. Mitochondria targeting nano agents in cancer therapeutics. Oncol. Lett. 2016, 12, 4887-4890. [CrossRef]

19. Patel, N.R.; Hatziantoniou, S.; Georgopoulos, A.; Demetzos, C.; Torchilin, V.P.; Weissig, V.; D'Souza, G.G. Mitochondria-targeted liposomes improve the apoptotic and cytotoxic action of sclareol. J. Liposome Res. 2010, 20, 244-249. [CrossRef]

20. Yamada, Y.; Harashima, H. Enhancement in selective mitochondrial association by direct modification of a mitochondrial targeting signal peptide on a liposomal based nanocarrier. Mitochondrion 2013, 13, 526-532. [CrossRef]

21. Battogtokh, G.; Gotov, O.; Kang, J.H.; Cho, J.; Jeong, T.H.; Chimed, G.; Ko, Y.T. Triphenylphosphine-docetaxel conjugate-incorporated albumin nanoparticles for cancer treatment. Nanomedicine 2018, 13, 325-338. [CrossRef]

22. Paleos, C.M.; Tsiourvas, D.; Sideratou, Z. Triphenylphosphonium decorated liposomes and dendritic polymers: Prospective second generation drug delivery systems for targeting mitochondria. Mol. Pharm. 2016, 13, 2233-2241. [CrossRef]

23. Wang, H.; Yin, H.; Yan, F.; Sun, M.; Du, L.; Peng, W.; Li, Q.; Feng, Y.; Zhou, Y. Folate-mediated mitochondrial targeting with doxorubicin-polyrotaxane nanoparticles overcomes multidrug resistance. Oncotarget 2015, 6, 2827-2842. [CrossRef]

24. Pathak, R.K.; Kolishetti, N.; Dhar, S. Targeted nanoparticles in mitochondrial medicine. Wiley Interdiscip. Rev. Nanomed. Nanobiotechnol. 2015, 7, 315-329. [CrossRef]

25. De Oliveira, M.R.; Nabavi, S.F.; Manayi, A.; Daglia, M.; Hajheydari, Z.; Nabavi, S.M. Resveratrol and the mitochondria: From triggering the intrinsic apoptotic pathway to inducing mitochondrial biogenesis, a mechanistic view. Biochim. Biophys. Acta 2016, 1860, 727-745. [CrossRef]

26. Joraholmen, M.W.; Basnet, P.; Tostrup, M.J.; Moueffaq, S.; Skalko-Basnet, N. Localized therapy of vaginal infections and inflammation: Liposomes-in-hydrogel delivery system for polyphenols. Pharmaceutics 2019, 11, 53. [CrossRef]

27. Zhou, H.B.; Chen, J.J.; Wang, W.X.; Cai, J.T.; Du, Q. Anticancer activity of resveratrol on implanted human primary gastric carcinoma cells in nude mice. World J. Gastroenterol. 2005, 11, 280-284. [CrossRef]

28. Sun, W.; Wang, W.; Kim, J.; Keng, P.; Yang, S.; Zhang, H.; Liu, C.; Okunieff, P.; Zhang, L. Anti-cancer effect of resveratrol is associated with induction of apoptosis via a mitochondrial pathway alignment. Adv. Exp. Med. Biol. 2008, 614, 179-186.

29. Van Ginkel, P.R.; Sareen, D.; Subramanian, L.; Walker, Q.; Darjatmoko, S.R.; Lindstrom, M.J.; Kulkarni, A.; Albert, D.M.; Polans, A.S. Resveratrol inhibits tumor growth of human neuroblastoma and mediates apoptosis by directly targeting mitochondria. Clin. Cancer Res. Off. J. Am. Assoc. Cancer Res. 2007, 13, 5162-5169. [CrossRef] 
30. Singh, G.; Pai, R.S.; Pandit, V. In vivo pharmacokinetic applicability of a simple and validated hplc method for orally administered trans-resveratrol loaded polymeric nanoparticles to rats. J. Pharm. Investig. 2014, 44, 69-78. [CrossRef]

31. Yang, T.; Wang, L.; Zhu, M.; Zhang, L.; Yan, L. Properties and molecular mechanisms of resveratrol: A review. Die Pharm. 2015, 70, 501-506.

32. Nassir, A.M.; Shahzad, N.; Ibrahim, I.A.A.; Ahmad, I.; Md, S.; Ain, M.R. Resveratrol-loaded plga nanoparticles mediated programmed cell death in prostate cancer cells. Saudi Pharm. J. SPJ Off. Publ. Saudi Pharm. Soc. 2018, 26, 876-885. [CrossRef]

33. Kang, J.H.; Battogtokh, G.; Ko, Y.T. Folate-targeted liposome encapsulating chitosan/oligonucleotide polyplexes for tumor targeting. AAPS PharmSciTech 2014, 15, 1087-1092. [CrossRef]

34. Zununi Vahed, S.; Salehi, R.; Davaran, S.; Sharifi, S. Liposome-based drug co-delivery systems in cancer cells. Mater. Sci. Eng. C Mater. Biol. Appl. 2017, 71, 1327-1341. [CrossRef]

35. Deshpande, P.P.; Biswas, S.; Torchilin, V.P. Current trends in the use of liposomes for tumor targeting. Nanomedicine 2013, 8, 1509-1528. [CrossRef]

36. Hattori, Y.; Shimizu, S.; Ozaki, K.I.; Onishi, H. Effect of cationic lipid type in folate-peg-modified cationic liposomes on folate receptor-mediated sirna transfection in tumor cells. Pharmaceutics 2019,11, 181. [CrossRef]

37. Jones, T.; Saba, N. Nanotechnology and drug delivery: An update in oncology. Pharmaceutics 2011, 3, 171-185. [CrossRef]

38. Dianat-Moghadam, H.; Heydarifard, M.; Jahanban-Esfahlan, R.; Panahi, Y.; Hamishehkar, H.; Pouremamali, F.; Rahbarghazi, R.; Nouri, M. Cancer stem cells-emanated therapy resistance: Implications for liposomal drug delivery systems. J. Control. Release Off. J. Control. Release Soc. 2018, 288, 62-83. [CrossRef]

39. Sun, X.; Yan, X.; Jacobson, O.; Sun, W.; Wang, Z.; Tong, X.; Xia, Y.; Ling, D.; Chen, X. Improved tumor uptake by optimizing liposome based res blockade strategy. Theranostics 2017, 7, 319-328. [CrossRef]

40. Riaz, M.K.; Riaz, M.A.; Zhang, X.; Lin, C.; Wong, K.H.; Chen, X.; Zhang, G.; Lu, A.; Yang, Z. Surface functionalization and targeting strategies of liposomes in solid tumor therapy: A review. Int. J. Mol. Sci. 2018, 19, 195. [CrossRef]

41. Park, J.W. Liposome-based drug delivery in breast cancer treatment. Breast Cancer Res. BCR 2002, 4, 95-99. [CrossRef]

42. Battogtokh, G.; Kang, J.H.; Ko, Y.T. Long-circulating self-assembled cholesteryl albumin nanoparticles enhance tumor accumulation of hydrophobic anticancer drug. Eur. J. Pharm. Biopharm. 2015, 96, 96-105. [CrossRef]

43. Ko, Y.T.; Bhattacharya, R.; Bickel, U. Liposome encapsulated polyethylenimine/odn polyplexes for brain targeting. J. Control. Release Off. J. Control. Release Soc. 2009, 133, 230-237. [CrossRef]

44. Solomon, M.A.; Shah, A.A.; D'Souza, G.G. In vitro assessment of the utility of stearyl triphenyl phosphonium modified liposomes in overcoming the resistance of ovarian carcinoma ovcar-3 cells to paclitaxel. Mitochondrion 2013, 13, 464-472. [CrossRef]

45. Zeng, F.; Ju, R.-J.; Li, X.-T.; Lu, W.-L. Advances in investigations on the mechanism of cancer multidrug resistance and the liposomes-based treatment strategy. J. Pharm. Investig. 2014, 44, 493-504. [CrossRef]

46. Bonechi, C.; Martini, S.; Ciani, L.; Lamponi, S.; Rebmann, H.; Rossi, C.; Ristori, S. Using liposomes as carriers for polyphenolic compounds: The case of trans-resveratrol. PLoS ONE 2012, 7, e41438. [CrossRef]

47. Ruttala, H.B.; Ko, Y.T. Liposomal co-delivery of curcumin and albumin/paclitaxel nanoparticle for enhanced synergistic antitumor efficacy. Colloids Surf. B Biointerfaces 2015, 128, 419-426. [CrossRef]

48. Emami, S.; Azadmard-Damirchi, S.; Peighambardoust, S.H.; Valizadeh, H.; Hesari, J. Liposomes as carrier vehicles for functional compounds in food sector. J. Exp. Nanosci. 2016, 11, 737-759. [CrossRef]

49. Abercrombie, M.; Ambrose, E.J. The surface properties of cancer cells: A review. Cancer Res. 1962, 22, 525-548.

50. Marchi, S.; Giorgi, C.; Suski, J.M.; Agnoletto, C.; Bononi, A.; Bonora, M.; De Marchi, E.; Missiroli, S.; Patergnani, S.; Poletti, F.; et al. Mitochondria-ros crosstalk in the control of cell death and aging. J. Signal Transduct. 2012, 2012, 329635. [CrossRef]

51. Alfonso-Loeches, S.; Urena-Peralta, J.R.; Morillo-Bargues, M.J.; Oliver-De La Cruz, J.; Guerri, C. Role of mitochondria ros generation in ethanol-induced nlrp3 inflammasome activation and cell death in astroglial cells. Front. Cell. Neurosci. 2014, 8, 216. [CrossRef] 
52. Gomes Dos Reis, L.; Lee, W.H.; Svolos, M.; Moir, L.M.; Jaber, R.; Windhab, N.; Young, P.M.; Traini, D. Nanotoxicologic effects of plga nanoparticles formulated with a cell-penetrating peptide: Searching for a safe pdna delivery system for the lungs. Pharmaceutics 2019, 11, 12. [CrossRef]

53. Redza-Dutordoir, M.; Averill-Bates, D.A. Activation of apoptosis signalling pathways by reactive oxygen species. Biochim. Biophys. Acta 2016, 1863, 2977-2992. [CrossRef]

54. Kamogashira, T.; Fujimoto, C.; Yamasoba, T. Reactive oxygen species, apoptosis, and mitochondrial dysfunction in hearing loss. BioMed Res. Int. 2015, 2015, 617207. [CrossRef]

55. Fleury, C.; Mignotte, B.; Vayssiere, J.L. Mitochondrial reactive oxygen species in cell death signaling. Biochimie 2002, 84, 131-141. [CrossRef]

(C) 2019 by the authors. Licensee MDPI, Basel, Switzerland. This article is an open access article distributed under the terms and conditions of the Creative Commons Attribution (CC BY) license (http://creativecommons.org/licenses/by/4.0/). 